\title{
Article
}

\section{Wettability studies of topologically distinct titanium surfaces}

Kulkarni, Mukta, Patil-Sen, Yogita, Junkar, Ita, Kulkarni, Chandrashekhar Vishwanath, Lorenzetti, Martina and Igli c, Ale `s Available at http://clok.uclan.ac.uk/13333/

Kulkarni, Mukta, Patil-Sen, Yogita, Junkar, Ita, Kulkarni, Chandrashekhar Vishwanath ORCID: 0000-0002-5621-4791, Lorenzetti, Martina and Igli ${ }^{2} \mathrm{C}$, Ale $s$ (2015) Wettability studies of topologically distinct titanium surfaces. Colloids and Surfaces B: Biointerfaces, 129 . pp. 47-53. ISSN 0927-7765

It is advisable to refer to the publisher's version if you intend to cite from the work. http://dx.doi.org/10.1016/j.colsurfb.2015.03.024

For more information about UCLan's research in this area go to http://www.uclan.ac.uk/researchgroups/ and search for <name of research Group>.

For information about Research generally at UCLan please go to http://www.uclan.ac.uk/research/

All outputs in CLoK are protected by Intellectual Property Rights law, including Copyright law. Copyright, IPR and Moral Rights for the works on this site are retained by the individual authors and/or other copyright owners. Terms and conditions for use of this material are defined in the policies page. 


\section{Accepted Manuscript}

Title: Wettability Studies of Topologically Distinct Titanium Surfaces

Author: Mukta Kulkarni Yogita Patil-Sen Ita Junkar Chandrashekhar V. Kulkarni Martina Lorenzetti Aleš Iglič

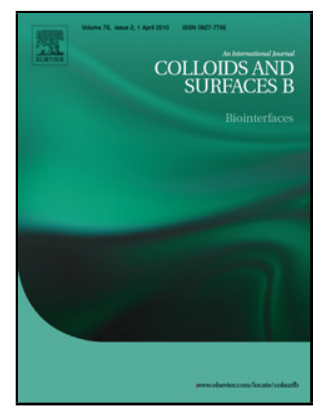

PII: S0927-7765(15)00158-7

DOI: http://dx.doi.org/doi:10.1016/j.colsurfb.2015.03.024

Reference: COLSUB 6964

To appear in: $\quad$ Colloids and Surfaces B: Biointerfaces

Received date: $\quad$ 28-11-2014

Revised date: 22-2-2015

Accepted date: $\quad$ 9-3-2015

Please cite this article as: M. Kulkarni, Y. Patil-Sen, I. Junkar, C.V. Kulkarni, M. Lorenzetti, A. Iglič, Wettability Studies of Topologically Distinct Titanium Surfaces, Colloids and Surfaces B: Biointerfaces (2015), http://dx.doi.org/10.1016/j.colsurfb.2015.03.024

This is a PDF file of an unedited manuscript that has been accepted for publication. As a service to our customers we are providing this early version of the manuscript. The manuscript will undergo copyediting, typesetting, and review of the resulting proof before it is published in its final form. Please note that during the production process errors may be discovered which could affect the content, and all legal disclaimers that apply to the journal pertain. 


\section{Highlights}

- Nanoscale morphologies of titanium dioxide by electrochemical anodization

- Wettability of Ti-Nanostructures studied by Contact Area Kinetics

- Improved time-dependent surface wettability

- Results suggests promising platform for biomedical applications

- Change in physicochemical surface properties of $\mathrm{TiO}_{2}$ nanostructures as a function of various diameters 


\title{
Wettability Studies of Topologically Distinct Titanium Surfaces
}

Mukta Kulkarni ${ }^{a} *$, Yogita Patil-Sen ${ }^{b}$, Ita Junkar ${ }^{c}$, Chandrashekhar V. Kulkarni ${ }^{b}$, Martina Lorenzetti ${ }^{c}$, Aleš Iglic ${ }^{a}$

* Corresponding author E-mail: mukta.kulkarni@,fe.uni-lj.si, Tel: +386 14768 235, Fax: $+38614268850$

${ }^{a}$ Laboratory of Biophysics, Faculty of Electrical Engineering, University of Ljubljana, Tržaška 25, Ljubljana 1000, Slovenia

${ }^{\mathrm{b}}$ Centre for Materials Science, School of Forensic and Investigative Sciences, University of Central Lancashire, Preston, PR1 2HE, United Kingdom

${ }^{\mathrm{c}}$ Jožef Stefan Institute, Jamova 39, Ljubljana 1000, Slovenia

\begin{abstract}
Biomedical implants made of titanium based materials are expected to have certain essential features including high bone-to-implant contact and optimum osteointegration, which are often influenced by the surface topography and physicochemical properties of titanium surfaces. The surface structure in the nanoscale regime is presumed to alter/facilitate the protein binding, cell adhesion and proliferation, thereby reducing post-operative complications with increased lifespan of biomedical implants. The novelty of our $\mathrm{TiO}_{2}$ nanostructures lies mainly in the high level control over their morphology and roughness by
\end{abstract}


mere compositional change and optimization of the experimental parameters. The present work focuses on the wetting behaviour of various nanostructured titanium surfaces towards water. Kinetics of contact area of water droplet on macroscopically flat, nanoporous and nanotubular titanium surface topologies was monitored under similar evaporation conditions. The contact area of the water droplet on hydrophobic titanium planar surface (foil) was found to decrease during evaporation, whereas the contact area of the droplet on hydrophobic nanorough titanium surfaces practically remained unaffected until the complete evaporation. This demonstrates that the surface morphology and roughness at the nanoscale level substantially affect the titanium dioxide surface-water droplet interaction, opposing to previous observations for microscale structured surfaces. The difference in surface topographic nanofeatures of nanostructured titanium surfaces could be correlated not only with the time-dependency of the contact area, but also with time-dependency of the contact angle and electrochemical properties of these surfaces.

Keywords: nanostructured titanium surfaces, biomedical implants, nanorough surfaces, wettability, surface electrochemical properties, time-dependent contact area

\section{Introduction}

Titanium (Ti) and its alloys exhibit highly promising biomaterial properties including high biocompatibility, great tensile strength, high corrosion resistance ${ }^{1}$ and have more resistance to the effects caused by fluids that are excreted or secreted from the human body. Owing to these outstanding properties, $\mathrm{Ti}$ alloys are widely used in biomedical applications, for instance, to produce/fabricate implants for hard tissue replacement. ${ }^{2-4}$ In order to improve the interactions with the living bone, ${ }^{4}$ the so-called "osteointegration" or "osseointegration" 
process, the implant surface made from Ti and its alloys needs to be physically and/or chemically modified. ${ }^{5,6}$. Speed, strength and degree of osteointegration depend mainly on the surface properties of implants, among which chemistry, physics, topography and wettability are known to be very crucial factors. ${ }^{4,7,8}$

The adsorption of proteins and, later, the adhesion of cells are time dependent phenomena which happen in steps. The initial response when the material is inserted in the biological surroundings is the adsorption of water molecules to its surface, which happens just within the first few nanoseconds. The reason is simply the abundance of water in the body. Many molecules, including proteins are dissolved in the aqueous medium. Therefore, understanding the wetting behaviour and the wettability kinetics of the material surface with water becomes an essential step, which has been focused in the present work.

As an example, we checked the interaction of water droplet with nanostructured titanium surfaces. Surface roughness and surface physicochemical properties (among them wettability) of the biomaterial are interrelated with the protein adsorption phenomenon., ${ }^{9,10,11}$ The water adsorption to the implant surface depends on the charge density of the surface which is strongly influenced by its nanoscale roughness. ${ }^{12,13}$ These factors have the major contribution in defining the implant surface-to-blood interactions as well as influencing the cell adhesion and, consequently, their growth and differentiation. ${ }^{14,15,16}$ After the initial adsorption of water molecules to the surface, the second stage involves the adsorption of proteins. Implant surfaces e.g. titanium dioxide $\left(\mathrm{TiO}_{2}\right)$ surfaces and cell membranes are both negatively charged; ${ }^{17}$ it is therefore necessary to have a mediator that shields the repulsive force between them. ${ }^{17,18}$ Proteins often work as these mediators thereby bridging the repulsive electrostatic interactions between equally charged surfaces. ${ }^{18}$ First, small proteins 
get adsorbed, due to their rapid transport to the surface, which over time are partially replaced by bigger ones having greater affinity towards the surface, ${ }^{19}$ following the "Vroman effect" theory. The binding of bigger proteins is sometimes mediated by previously bounded smaller proteins. ${ }^{14}$ Smaller proteins are also known to mediate the adhesion of cell glycocalyx (i.e. glycoprotein-polysaccharide cell coating). ${ }^{17,18}$

Surface properties, including wettability and charge, influence the adsorption of proteins which mediate the adhesion of bacteria and cells to the implant. ${ }^{7,8}$ Some cells prefer to attach to hydrophilic surfaces, while others have characteristic attraction towards hydrophobic ones. ${ }^{20-22}$ Generally, hydrophobic surfaces are considered to be more protein-absorbent than hydrophilic ones, due to the strong hydrophobic interactions. ${ }^{9,23}$ However, this could cause conformational changes or, sometimes, denaturation of proteins and, thus, lower the proliferation of cells on such surfaces. It is reported that biomaterial surfaces with moderate hydrophilicity display improved cell growth and biocompatibility. ${ }^{13}$ Nevertheless, cell adhesion can decrease as the material becomes too hydrophilic. Cell proliferation also depends on an appropriate orientation of proteins which gives guidance to the cells. Time dependent conformational changes of adsorbed proteins as well as adhesion kinetics and strength of protein binding ${ }^{9,24}$ are, therefore, of primary importance. Another key factor to tailor the biological response is the surface electric charge of the implant. Most of the plasma proteins are negatively charged at physiological $\mathrm{pH}(\mathrm{pH}=7.4)$, so that repulsive electrostatic interactions are expected to occur towards the negatively charged Ti-implant surface ${ }^{17,18}$. Once again, the protein conformational changes play an important role. ${ }^{25}$ The optimization of the physico-chemical surface properties ${ }^{17,18}$, in this manner, becomes a crucial parameter to be considered while designing the biomedical implants. ${ }^{26}$ 
The surface topography considerably alters the cellular behaviour in terms of adhesion, spreading, migration, proliferation and signalling. ${ }^{7}$ For instance, fibroblasts and epithelial cells adhere more strongly to smooth surfaces, whereas rough surfaces aid in osteoblastic proliferation and collagen synthesis. ${ }^{27}$ In general, larger the effective (real) surface area, higher is the degree of bone-to-implant (BIC) contact, which is one of the important elements for the success of orthopaedic implants. ${ }^{28}$ It should be also stressed that micro and nanoscale patterns are not only observed in implant substrates (in vitro) but are also seen in vivo, for example, fibrils and fibre bundles (collagen and fibrin), ${ }^{29}$ rough surfaces (crystal deposit in bone) and porous membranes (basement membranes). ${ }^{30}$ These naturally-occurring hierarchical patterns play an important role in many biological tissues, including bone, teeth, and cartilage $e^{29,31}$ as their surface properties, such as wettability and topography (and their interdependence), determine the adhesion and proliferation of cells in biological systems. ${ }^{15,16,18,32}$ Moreover, nanostructured surfaces are shown to play an important role in osteoblast proliferation as well as in mimicking natural bones. ${ }^{33-35}$ In fact, cells are presumed to sense and respond to such nanoscale topographical attributes also through membrane deformation and stretching. ${ }^{18,36,37}$ All these surfaces own a specific nanostructure which enables the desirable adsorption of proteins which further guide cells.

Within the biomedical community, the nanorough $(1-100 \mathrm{~nm})$ surfaces are becoming more popular than macro $(10 \mu \mathrm{m}$ to $1 \mathrm{~mm})$ and micro $(1-10 \mu \mathrm{m})$ rough surfaces. Nanoscale topography increases the effective (real) nanoscale surface area and, thus, enhances the ability to withstand more molecules, like proteins. Due to higher surface charge density at nanoscale sharp edges, nanoscale sharp edges may facilitate monovalent and divalent cationmediated binding/adhesion of proteins to the surface. ${ }^{17,18}$ The layer of the adsorbed proteins and other molecules, in this manner, improves the cell attachment to the surface. ${ }^{38}$ In the 
current study, we have employed nanorough titanium dioxide surfaces, made of nanotubes and nanopores, and a microrough surface (titanium foil). The nanostructured surfaces were fabricated by electrochemical anodization. ${ }^{39}$ Parameters were tuned to obtain macroscopically flat, but locally rough nanoporous (15 nm pores) and nanotubular surfaces (diameters 50 and $100 \mathrm{~nm})$. Studies demonstrate that the nanoscale morphologies display different wettability behaviour as compared to their microscale counterparts. ${ }^{40,41}$

In general, the physics of liquid droplet interactions with nanostructured ${ }^{40}$ and microstructured $^{41}$ surfaces have been the subject of increasing interest in the past few years. Most of the theoretical descriptions assumed that either the liquid drop penetrates into the surface invaginations (Wenzel regime) or the drop stays on the microstructured surface protrusions (Cassie regime) and does not contact the bottom plate. ${ }^{41}$ Seldom, the intermediate situation is considered, where the drop partially protrudes into the invaginations of the microstructured surface, i.e. due to the roughness of the microscale protrusions on their top (Wenzel-Cassie regime). ${ }^{41}$ We show in this work that the $\mathrm{TiO}_{2}$ nanostructures have a specific influence on the interaction between the water droplet and the surface. To some extent, this makes the droplet behaviour on $\mathrm{TiO}_{2}$ nanotubular surface different from what expected on the microscale structured surfaces, based on the validity of either Wenzel or Cassie law. We propose that the specific behaviour of the nanostructured surfaces may have an important effect on the features that are crucial for designing orthopaedic implants, such as protein adsorption, cell adhesion and osteointegration. In addition, we measured the surface charge properties of the pristine and nanostructured titanium, to verify the occurrence of any variation in terms of isoelectric point (IEP) and zeta $(\zeta)$. 


\section{Experimental}

\section{Materials}

Ti-foils of $0.1 \mathrm{~mm}$ thickness (99.6 \% purity) were obtained from Advent Research Materials, England. Distilled water used during the entire study was purified by Werner - Reverse osmosis equipment. Hydrofluoric acid (HF) and the solvents, namely Ethylene Glycol (EG), ethanol, and acetone, were purchased from Sigma Aldrich, Germany and used without further purification.

\section{Fabrication of $\mathrm{TiO}_{2}$ Surfaces}

The Ti-nanostructures were fabricated according to the electrochemical anodization method published earlier, ${ }^{1,39}$ although using slightly different parameters, as described below. Prior to anodization, Ti-foils were degreased by successive ultra-sonication steps in acetone, ethanol and deionized water for 5 min each and dried under the nitrogen stream. EG based electrolytes were used to grow Ti-nanostructures with specific compositions, as listed in

Table 1. All the anodization experiments were carried out at room temperature $\left(\sim 20{ }^{\circ} \mathrm{C}\right)$ in a

two-electrode system, using the titanium foil as the working electrode and a platinum gauze as the counter electrode. As-formed nanostructures were allowed to stand in ethanol for two hours in order to remove organic components from the electrolytic solution. This step was 
followed by washing of the nanostructures with distilled water and drying under nitrogen stream.

It should be stressed at this point that the hydrophobic/hydrophilic character of the $\mathrm{TiO}_{2}$ nanopore/nanotube surface may depend on aging, where the effect of aging can be strongly modified/abolished by annealing or other methods. ${ }^{40,42,43}$ For example by the aid of plasma treatment technique, the hydrophobic character of aged $\mathrm{TiO}_{2}$ nanopore/nanotube surface will be reversed to hydrophilic, possibly due to the removal of surface contaminants, such as carbon. It was shown recently that wettability of $\mathrm{TiO}_{2}$ nanosurfaces can change with time. ${ }^{41}$ Keeping this in mind, in the current work we deliberately used two months-aged surfaces, which showed a hydrophobic (i.e. contact angle $>90^{\circ}$ ) or weakly hydrophilic character.

\section{Atomic Force Microscopy (AFM)}

Topographic features of Ti-foil and Ti-nanostructured surfaces were examined by atomic force microscopy (Solver PRO, NT-MDT, Russia) in tapping mode in air. The samples were scanned with the standard Si cantilever at a constant force of $22 \mathrm{~N} / \mathrm{m}$ and resonance frequency of $325 \mathrm{kHz}$ (10 nm tip radius, $95 \mu \mathrm{m}$ tip length). The average surface roughness $\left(R_{a}\right)$ was calculated from $3 \times 3 \mu m^{2}$ image areas. The results are shown as the average $R_{a}$ from five different areas.

\section{Scanning Electron Microscopy (SEM)}

High contrast images of nanostructural morphology of Ti-surfaces were obtained by Scanning Electron Microscopy (Hitachi FE-SEM S4800). All samples were used without gold sputtering, as the untreated samples already display images with reasonably good contrast. 


\section{Contact Distance (D) Measurements}

Water droplet contact areas, expressed in terms of contact diameter $(D)$ of the curve fitted to the droplet image (see Figs. 3, 5), on all the Ti-surfaces were measured at regular intervals using the Contact Angle Instrument (First Ten Ångstroms, Inc. USA, FTA1000 series). The measurement system consisted of a sample stage, vertically fitted Hamilton micro-syringe to place the water droplet on the sample and the camera mount - TV lens camera with Extension tube set $40 \mathrm{~mm}$ (Edmund optics, Japan). Images were captured and analysed for contact areas using the FTA32 Video 2.0 software. All the measurements were performed at room temperature $\left(27 \pm 1^{\circ} \mathrm{C}\right)$.

\section{Surface charge measurements by streaming potential}

The surface charge analysis was accomplished using an electrokinetic analyser (SurPASS, Anton Paar $\mathrm{GmbH}$, Austria). The $\mathrm{pH}$ dependence (titration curve) of zeta potential ( $\zeta$ potential) and isoelectric point (IEP) were obtained in $0.001 \mathrm{~mol} / 1$ potassium chloride ( $\mathrm{KCl}$ p.a., Carl Roth $\mathrm{GmbH}$, Germany) solution by streaming potential measurements.

\section{Results and Discussion}

\section{Nanoscale Morphology of Ti-Surfaces}

The morphological features of $\mathrm{TiO}_{2}$ nanostructures were determined by SEM technique. High contrast images clearly define the dimensions of nanopores and nanotubes as shown in Fig. 1. SEM images demonstrate the nanostructural uniformity and hollowness of the surfaces as expected. The nanopores present an average diameter of $15 \mathrm{~nm}$ with standard deviation of $20 \%$. Nanotubes samples have average $50 \mathrm{~nm}$ and $100 \mathrm{~nm}$ diameters with standard deviations of $10 \%$ and $5 \%$ respectively. 
The topographical features of the nanostructures investigated by AFM are shown in Fig. 2 . The pristine (non-anodized) Ti-foil used for this study was flat at the macroscopic level, but presented local vertical distortions (vertical roughness) by AFM imaging at the microscopic level. The estimated vertical roughness of the Ti-foil was around $28 \mathrm{~nm}$. Imaging of nanoporous Ti-surface (pore diameter of $15 \mathrm{~nm}$ ) was not possible due to the excessive size of the AFM tip, which produced practical artifacts on the surface. The situation was almost similar for the Ti-surface with $50 \mathrm{~nm}$ nanotubes, which appeared to be closed rather than open (hollow) structures. This attribute was also reflected by a lower vertical roughness value (around $20 \mathrm{~nm}$ ) as compared to the pristine Ti-foil. It was, however, possible to get better understanding of topographic features of Ti-nanotubes of $100 \mathrm{~nm}$ diameter as shown in Fig.2. The AFM tip could penetrate the hollow into the $100 \mathrm{~nm}$ diameter nanotubes, providing a clear picture of the open nanotube structures. This was beneficial to validate the presence of nanotubes and their variable depth in contrast to 2-dimensional SEM micrographs. The surface vertical roughness was estimated to be around $40 \mathrm{~nm}$ but the actual vertical roughness is presumed to be much higher, as the AFM tip could not distinguish the interstitial sites among the nanotubes and was not able to reach the bottom of the nanotube surface. Therefore, the AFM study revealed slightly different information than SEM, due to its technical limitations as described above.

\section{Wettability Studies of Ti-nanostructures by Contact Area Kinetics}

For each experiment, a single droplet of $\sim 10 \mu \mathrm{l}$ distilled water was placed on the Ti surface using the Hamilton micro-syringe. The images were captured immediately after placing the drop on the surface $(t=0)$ and every five minute thereafter, until the complete evaporation of the drop. Fig. 3 displays images recorded after every 5 min until evaporation of the droplet (observed at $30 \mathrm{~min}$ ). The largest planar distance between end points of a curve fitted to the 
side-view image of water droplet was defined as contact diameter $\mathrm{D}$, which simply equals the diameter of the contact area (Figs. 3, 5).

As expected, ${ }^{41}$ the D value for macroscopically flat and weakly hydrophilic Ti-foil changed significantly with time, especially in the later stages of evaporation, i.e. after 15 min (Fig. 4). The roughness of Ti-foil surface, albeit locally distorted and not ideally smooth ${ }^{17}$, was not sufficient to hinder the receding of the droplet edge (contact line), i.e. to decrease the value of D. Therefore, the droplet evaporation after certain time, ${ }^{41}$ executed from the outer edges along $360^{\circ}$, caused the considerable decrease in the D value with time (see Fig. 4). In contrast, the nanoporous and nanotubular surfaces, due to their enhanced roughness (see Figs. 1 and 2), exhibited constant D values. This may be attributed to the penetration (at least partial) of the water into the hollow interiors of the nanopores/nanotubes and also into intermediate space among nanotubes (probably in accordance with mixed Wenzel-Cassie regime, ${ }^{41}$ explained later). Due to the liquid penetration, the effective area wetted by water in case of nanorough surfaces is larger than the area of the ideally smooth surface (which equals to $\pi D^{2} / 4$, see Fig. 5). The elevated wetting of the upper part of hollow interiors of the nanopores/nanotubes may result in an increase in attractive and frictional forces, thereby restricting the receding of the droplet edge (contact line) in the lateral direction and keeping the D value practically unchanged or minimally changed (Fig. 4). The topographical roughness of the $\mathrm{TiO}_{2}$ nanostructured surfaces in vertical direction (as shown in Fig.2) may additionally contribute towards hindrance of the receding droplet, among others due to increased frictional forces.

As evident from Fig.4, the water droplet contact angle decreases gradually with time during the whole evaporation process in all the presented cases. This phenomenon was observed already in the past, but exclusively on hydrophilic surfaces. The explanation of such 
behaviour of the contact angle is still not clear. ${ }^{41}$ It was further shown that the evaporating water droplet on a hydrophobic surface retains a constant contact angle, while, concomitantly, the contact diameter decreases. ${ }^{41}$ On the other hand, the water droplet on a hydrophilic surface initially preserve a constant contact diameter, while the contact angle decreases from the very beginning. ${ }^{41}$ Once the receding value of contact is reached, both the contact diameter and the contact angle decrease. ${ }^{41}$ In our case (Fig. 4) the nanostructured $\mathrm{TiO}_{2}$ surfaces behave very differently, as described above. Namely, on nanostructured $\mathrm{TiO}_{2}$ surfaces the evaporating water droplet preserves/keeps its contact diameter despite of its hydrophobic nature (contact angle $>90^{\circ}$ ) (Figs. 3b,c). On the other hand, the contact diameter of the water droplet on Titanium foil recedes during the evaporation process (Fig. 3a).

\section{Interaction Behaviour of Water Droplet with Ti-Nanostructures}

According to Wenzel law, the increased roughness of the microstructured surfaces (and thus enhanced effective surface areas) make the hydrophobic surface even more hydrophobic and hydrophilic surface even more hydrophilic. ${ }^{41}$ On the other hand the contact area of Cassie droplet is determined by the ratio of contact surface area of the drop with the microstructured surface (top surface of protrusions) to the total top surface. ${ }^{41}$

Our results indicate that the behaviour of water droplet on the $\mathrm{TiO}_{2}$ nanoporous and nanotubular surfaces is only partially governed by the Wenzel law or the combined WenzelCassie law. ${ }^{41}$ Nevertheless, it is hard to estimate the degree of penetration of the water in the interior of the nanotubes and nanopores and the role of the nanoscale vertical surface roughness. The measured values of the initial contact angle (at time zero) for $15 \mathrm{~nm}$ and 50 $\mathrm{nm}$ nanotubular surfaces and nanoporous surface (not shown) are larger than the corresponding value for Ti-foil and are increasing from $50 \mathrm{~nm}$ to $15 \mathrm{~nm}$ nanotubular surface 
and further to nanoporous surface. This is not in agreement with the Cassie law, since the top surface (ring) area of the $\mathrm{TiO}_{2}$ nanotubular surfaces increases following the order from 100 $\mathrm{nm}, 50 \mathrm{~nm}$ to $15 \mathrm{~nm}$ nanotubular surface and finally to nanoporous surface. On the other hand, the initial contact area for $100 \mathrm{~nm}$ nanotubular surface appears to be smaller than the initial contact area for Ti-foil surface. Therefore from these contact angle values it cannot be confirmed whether the droplet partially (Wenzel-Cassie droplet) or fully (Cassie droplet) resides on the surface of the nanotubes. ${ }^{41,44}$

The wetting phenomenon of Ti-foil can be correlated to the droplet retraction due to the hysteresis of contact angles from slightly rough surfaces. ${ }^{45}$ However, the wetting of nanorough surfaces $\left(\mathrm{TiO}_{2}\right.$ nanopores or nanotubes), appears to be much more complicated and needs more complex models like Wenzel model ${ }^{46,47}$ or Cassie-Baxter model ${ }^{48}$ or a combination of them. ${ }^{41}$ The nanorough surfaces may act as adsorptive materials at the nanoscale that can wet the interior and the intermediate regions of nanopore/nanotube surfaces, as shown by the schematics in Fig. 5.

\section{The influence of different diameters of nanotubes on the surface charge}

The surface charge of the samples was estimated using the surface streaming potential technique and expressed as the $\zeta$-potential dependence on the $\mathrm{pH}$ (Fig. 6). The titanium foil showed its IEP at the most acid $\mathrm{pH}(\mathrm{pH}=3.74)$ among the samples. The nanostructured surfaces with nanotubes of $15 \mathrm{~nm}, 50 \mathrm{~nm}$ and $100 \mathrm{~nm}$ in diameter presented their IEP at $\mathrm{pH}$ 4.70, 4.58 and 5.18, respectively. The more acidic IEP for titanium foil than for the anodized titanium is partially due to the amorphous oxide structure (short range order), naturally formed by passivation, which may influence the stability and density of the surface hydroxyl 
groups. $^{25,49,50}$ On the other hand, the stoichiometric titanium dioxide nanotubes displayed IEP at more basic $\mathrm{pH}$ than titanium. In accordance with Pedimonte et al., ${ }^{50}$ a general trend for the nanostructured surfaces was observed, i.e. the IEP became more basic with the increase in pore size. Thus, the nanotube diameters might have an influence on the local surface chemistry at the top-edge of the nanotubes and, consequently, on a different coordination hydroxyl groups, which results in the IEP shift for the $100 \mathrm{~nm}$ diameter nanotubular surface. At $\mathrm{pH}$ higher than the IEP a negative surface charge exists, therefore at physiological $\mathrm{pH}$ all the samples appeared negatively charged. Significant differences in terms of measured $\zeta$ potential values were found: the titanium foil showed the highest negative $\zeta$-potential, followed by the series of the nanostructured samples, $15 \mathrm{~nm}$ diameter nanotubes, $50 \mathrm{~nm}$ diameter nanotubes and $100 \mathrm{~nm}$ diameter nanotubes, in sequence. This may be partially explained by increasing top surface (ring) area of $\mathrm{TiO}_{2}$ nanotubular surface following the order from $100 \mathrm{~nm}, 50 \mathrm{~nm}$ to $15 \mathrm{~nm}$ diameter nanotubes with the highest top surface area. In addition, the total length of the inner and outer edges of the nanotubes (calculated per unit area of the nanotubular surface) is the largest for $15 \mathrm{~nm}$ nanotubular surface which may also contribute to more negative (average) surface potential for $15 \mathrm{~nm}$ nanotubes (see for explanation Gongadze et al. ${ }^{18}$ ). Also, an effect of the considerable vertical surface roughness of the $100 \mathrm{~nm}$ diameter nanotubes on the average surface charge density cannot be excluded. Among all the samples, the Ti surface covered by $100 \mathrm{~nm}$ diameter nanotubes appeared to exhibit at the nanoscale level the most pronounced topographical variation in the vertical direction (see Fig. 2) and also the most hydrophilic character (i.e. the smallest contact angle). Taken all together, the described topographical (Figs.1,2) electrochemical (Fig. 6) features of $100 \mathrm{~nm}$ nanotubular surface are proposed to contribute to least negatively charged $100 \mathrm{~nm}$ nanotubular surface (having $\zeta$-potential $\approx-35 \mathrm{mV}$ at physiological $\mathrm{pH})$. The observed differences in $\zeta$-potential and IEP values between 
different diameter nanotubular surfaces clearly indicate the important influence of nanotubes' diameter and vertical topographical variation (roughness) on the electrochemical properties of $\mathrm{TiO}_{2}$ nanotubular surfaces.

\section{Conclusions}

We have successfully fabricated well-defined titanium-nanorough surfaces using electrochemical anodization by a systematic optimization of the experimental conditions. The titanium dioxide nanorough surfaces demonstrably hinder the receding of the contact area during the evaporation of water droplet. The exposure of much larger effective (real) surface area and the consequent wettability of the nanorough surfaces, as compared to micro- and macroscopically rough ones, are potentially advantageous properties while developing biomedical implants. ${ }^{51-53}$ Moreover, the predicted behaviour of nanorough surfaces, with regards to the suppression of receding of contact area, could further contribute towards an improved biological response in terms of adhesion of proteins, membranous components and cells to the implant surfaces. ${ }^{14,18,54,55}$ The larger effective (real) surface area of the implant generated by the nanostructuring of its surface is expected to improve the bone-to-implant contact, which is one of the important elements for the success of orthopaedic implants.

\section{Acknowledgements}

M.K., I.J. and A.I. would like to acknowledge Slovenian Research Agency (ARRS) for the financial support. The authors are grateful to Anca Mazare for SEM figures (Fig.1).

\section{References}

1. P. Roy, S. Berger and P. Schmuki, Angew Chem Int Ed Engl, 50 (2011) 2904. 
2. C. N. Elias, J. H. C. Lima, R. Valiev and M. A. Meyers, JOM, 60 (2008) 46.

3. D. F. Williams, Biomaterials, 29 (2008) 2941.

4. S. Anil, P. S. Anand, H. Alghamdi and J. A. Jansen, Implant Dent - A Rapidly Evolving Practice, ed. I. Turkyilmaz, InTech, (2011) 83.

5. A. Popelka, I. Novak, M. Lehocky, M. Spirkova, F. Bilek, Molecules, 17 (2012) 762.

6. J. L. Garcia, J. Pachernik, M. Lehocky, P. Humpolicek, P. Saha, Prog Coll Pol Sci, 138 (2010) 89.

7. M. Ventre, F. Causa and P. A. Netti, J Roy Soci Inter, 9 (2012) 2017.

8. Y. Tamada and Y. Ikada, J Coll Interf Sci, 155 (1993) 155.

9. L., C. Siedlecki and A. Christopher, Biomaterials, 28 (2007) 3273.

10. G. Sigal, M. Mrksich, and G. Whitesides, J Am Chem Soc, 120 (1998) 3464

11. T. Akkas, C. Citak, A. Sirkecioglu and F Seniha G uner, Polym Int, 62 (2013) 1202

12. E. Gongadze, A. Velikonja, Š. Perutkova, P. Kramar, A. Maček-Lebar, V. Kralj-Iglič and A. Iglič, Electrochim Acta, 126 (2014) 42.

13. Application note 17: Influence of topography and wettability on biocompatibility: http://www.biolinscientific.com/zafepress.php?url=\%2Fpdf $\% 2 \mathrm{FAttension} \% 2 \mathrm{FApplication} \% 2$ 0Notes\%2FAT AN 17 roughbio.pdf

14. M. Kulkarni, A. Flašker, M. Lokar, K. Mrak-Poljšak, A. Mazare, A. Artenjak, S. Čučnik, S. Kralj, A. Velikonja, P. Schmuki, V. Kralj-Iglič, S. Sodin-Semrl and A. Iglič, Int J Nanomed, 10 (2015) 1359.

15. K. C. Popat, L. Leoni, C. A. Grimes and T. A. Desai, Biomaterials, 28 (2007) 3188.

16. S. Bauer, J. Park, K.v.d. Mark, and P. Schmuki, Acta Biomater, 4 (2008) 1576.

17. M. Kulkarni, A. Mazare, E. Gongadze, Š. Perutkova, V. Kralj-Iglič, I. Milošev, P. Schmuki, A. Iglič and M. Mozetič, Nanotechnology, 26 (2015) 062002. 
18. E. Gongadze, D. Kabaso, S. Bauer S, T. Slivnik, P. Schmuki, U. van Rienen and A. Iglič, Int J Nanomed, 6 (2011) 1801.

19. P. Roach, D. Englin, K. Rohde and C. C. Perry, J Mater Sci Mater Med, 18 (2007) 1263

20. A. J. García, Poly Regenerat Med, ed. C. Werner, Springer Berlin Heidelberg, 203 (2006) 171.

21. M. Lotfi, M. Nejib and M. Naceur, Advances in Biomaterials Science and Biomedical Applications, Prof. Rosario Pignatello (Ed.), ISBN: 978-953-51-1051-4, InTech, DOI: 10.5772/53542, (2013) 207.

22. K. C. Hazen, D. L. Brawner, M. H. Riesselman, M. A. Jutila and J. E. Cutler, Infect Immun, 59 (1991) 907.

23. A. Kongde, T. Bechtold and L. Teufel, J Appl Polym Sci, 96 (2005) 1421.

24. F. Fang, J. Satulovsky and I. Szleifer, Biophys J, 89 (2005) 1516.

25. M. Textor, C. Sittig, V. Frauchiger, S. Tosatti and D. Brunette, Titanium in Medicine, Editors: D. Brunette, P. Tengvall, M. Textor, P. Thomsen Springer Verlag, Heidelberg and Berlin, (2001) 171.

26. R. E. Baier, J Mater Sci Mater Med, 17 (2006) 1057.

27. B. Boyan, D. Dean, C. Lohmann, D. Cochran, V. Sylvia and Z. Schwartz, in Titanium in Medicine, Editors: D. Brunette, P. Tengvall, M. Textor, P. Thomsen Springer Verlag, Heidelberg and Berlin, 17 (2001) 561.

28. W. A. Soskolne, S. Cohen, L. Sennerby, A. Wennerberg and L. Shapira, Clin Oral Implant Res, 13 (2002) 86.

29. L. Bozec, G. van der Heijden, and M. Horton, Biophys J, 92 (2007) 70.

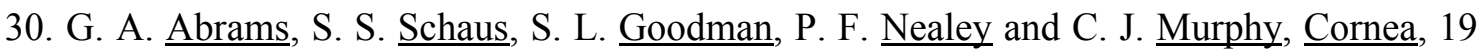
(2000) 57.

31. L. Bozec and M. Horton, Biophys J, 88 (2005) 4223. 
32. K. L. Mittal ed. Contact angle, wettability and adhesion. Vol. 4. CRC Press (2006).

33. R. Kane and P. X. Ma, Mater Today, 16 (2013) 11.

34. L. Zhang and T. J. Webster, Nano Today, 4 (2009) 66.

35. E. Engel, A. Michiardi, M. Navarro, D. Lacroix and J. A. Planell, Trends in Biotechnol, $26(2008) 39$.

36. A. Curtis and C. Wilkinson, Biomaterials, 18 (1997) 1573.

37. J. Y. Lim and H. J. Donahue, Tissue eng, 13 (2007) 1879.

38. E. Gongadze, D. Kabaso, S. Bauer, J. Park, P. Schmuki and A. Iglič, Mini Rev Med Chem, 13 (2013) 94.

39. D. Kowalski, D. Kim and P. Schmuki, Nano Today, 8 (2013) 235.

40. D. H. Shin, T. Shokuhfar, C. K. Choi, S. H. Lee and C. Friedrich, Nanotechnology 22 (2011) 315704 .

41. J. Berthier and K. A. Brakke, The Physics of Microdroplets, Scrivener Publishing, 201

42. N. Verplanck, Y. Coffinier, V. Thomy and R. Boukherroub, Nanoscale Res Lett, 2 (2007) 577

43. Z. Zhou, F. Li, Q. Song, T. Yi, X. Hou and C. Huang, Chem Lett, 34 (2005) 1298.

44. D. Quéré, Nat Mater, 1 (2002) 14.

45. R. J. Good, J Adhes Sci Technol, 6 (1992) 1269.

46. R. N. Wenzel, Ind Eng Chem, 28 (1936) 988.

47. R. N. Wenzel, J Phys Coll Chem, 53 (1949) 1466.

48. A. B. D. Cassie and S. Baxter, Trans Faraday Soc, 40 (1944) 546.

49. S. Roessler, R. Zimmermann, D. Scharnweber, C. Werner and H. Worch, Coll Surf B: Biointerfaces, 26 (2002) 387. 
50. B. J. Pedimonte, T. Moest, T. Luxbacher, C. von Wilmowsky, T. Fey, K. A. Schlegel and P. Greil, Acta Biomater 10 (2014) 968.

51. E. Ogorevc, V. Kralj-Iglic, P. Veranic, Radiol and Oncol, 47 (2013) 197.

52. N. Recek, M. Mozetic, M. Jaganjac, L. Milkovic, N. Zarkovic, A. Vesel, Vacuum, 98 (2013) 116.

53. A. Vesel, K. Elersic, M. Modic, I. Junkar, M. Mozetic, Materials, 7 (2014) 2014.

54. V. Kralj-Iglic, Int J Nanomed, 7 (2012) 3596.

55. M. Jaganjac, A. Vesel, L. Milkovic, N. Racek, M. Kolar, N. Zarkovic, A. Latiff, K. S. Karin-Kleinschek, M. Mozetic, J Biomed Mater Res A, 102 (2014) 2305.

\section{Figure Captions}

Fig. 1 SEM Micrographs of Ti-nanostructures: Scanning Electron Microscopy images of Titanium nanopores of diameter $15 \mathrm{~nm}$, nanotubes of $50 \mathrm{~nm}$ and nanotubes of $100 \mathrm{~nm}$ diameter, Scale bar is $200 \mathrm{~nm}$.

Fig. 2 AFM Images of Ti-nanostructures: Atomic Force Microscopy images of Titanium pristine foil, nanotubes of $50 \mathrm{~nm}$ and nanotubes of $100 \mathrm{~nm}$ diameter. Zoomed regions (along vertical 'z-direction') show further topological details.

Fig. 3 Measurement of Water Droplet Contact Diameter with Time: Contact diameter of the contact area between the droplet and Ti-surface is depicted with D (measured in millimeters) for each surface as shown in a) for pristine Ti-foil, b) for $\mathrm{TiO}_{2}$-nanotubes $(50 \mathrm{~nm}$ 
diameter) and c) for $\mathrm{TiO}_{2}$-nanotubes (100 nm diameter). Red arrows were used to denote exact end points while yellow curves (e.g. yellow block arrows) defined the shape of the droplet.

Fig. 4 Time-dependence of Contact Diameter D of Various Ti-Nanostructures: Contact diameter $\mathrm{D}$ of the droplet (see also Fig. 5) remained practically unaltered for nanorough surfaces whereas it changed considerably for flat Ti-surface.

Fig. 5 Schematic Diagrams of Wetting of Ti-Nanostructures: Wetting of Ti-foil drives the retraction of the droplet, whereas the nanoporous and nanotubular $\mathrm{TiO}_{2}$ surfaces are wetted differently by the droplet. Due to changed interfacial forces, the receding of contact area of the drop on $\mathrm{Ti}_{2}$-nanostructured surfaces is hampered and thus the contact diameter D remains nearby unchanged. (Blue shading is used to indicate aqueous regions whereas arrow depicts the path of wetting nanotube surface).

Fig. 6 The pH dependences of $\zeta$-potential for Ti-foil and $\mathrm{TiO}_{2}$ Nanotubular Surfaces : $\zeta$-potential for $\mathrm{Ti}$-foil and $\mathrm{TiO}_{2}$ nanotubular surfaces with $15 \mathrm{~nm}, 50 \mathrm{~nm}$, and $100 \mathrm{~nm}$ diameters as a function of $\mathrm{pH}$ in water at $0.001 \mathrm{~mol} / 1$ concentration of $\mathrm{KCl}$. 


\section{Table}

Table 1. Anodization Conditions used for fabrication of Ti-Nanostructures

\begin{tabular}{llll}
\hline Diameter of & Electrolyte Solution & Potential (V) & $\begin{array}{l}\text { Time of } \\
\text { Nanostructure }\end{array}$ \\
& & & Anodization \\
& & & $($ hour $)$ \\
\hline Nanopores $15 \mathrm{~nm}$ & $\mathrm{EG}+6 \mathrm{M}$ water $+0.2 \mathrm{M} \mathrm{HF}$ & 10 & 1 \\
Nanotubes $50 \mathrm{~nm}$ & $\mathrm{EG}+8 \mathrm{M}$ water $+0.2 \mathrm{M} \mathrm{HF}$ & 20 & 2.5 \\
Nanotubes $100 \mathrm{~nm}$ & $\mathrm{EG}+8 \mathrm{M}$ water $+0.2 \mathrm{M} \mathrm{HF}$ & 58 & 2.5 \\
\hline
\end{tabular}



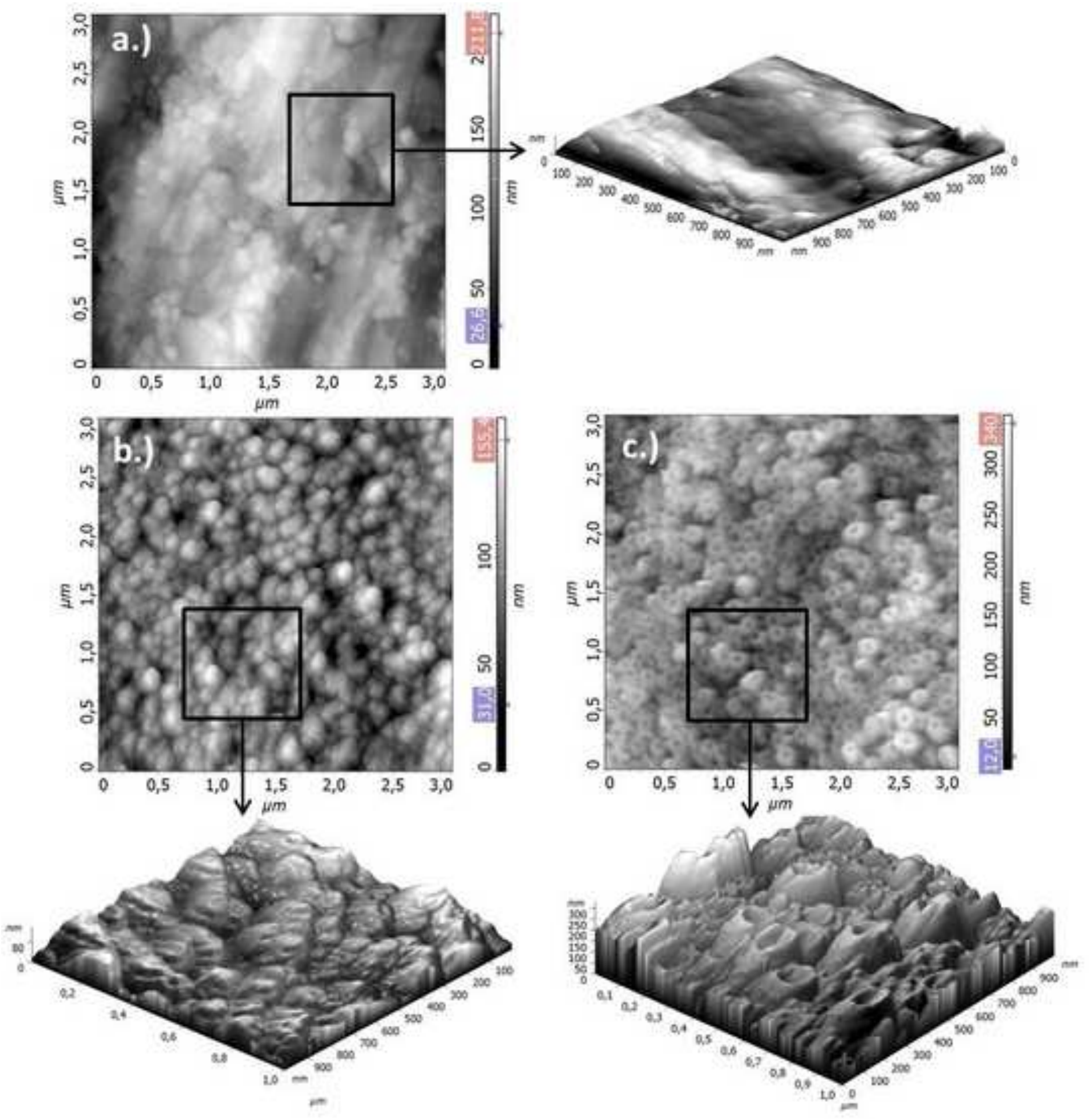

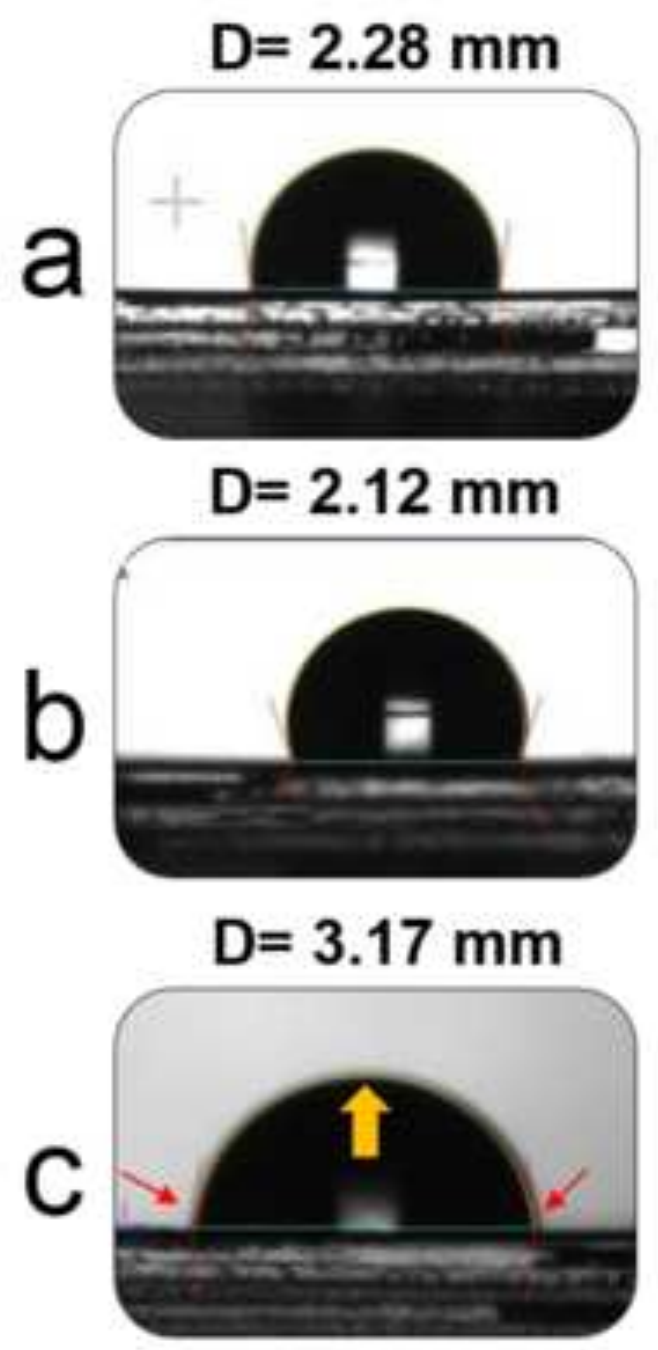

$$
\mathrm{t}=\mathbf{0} \min
$$
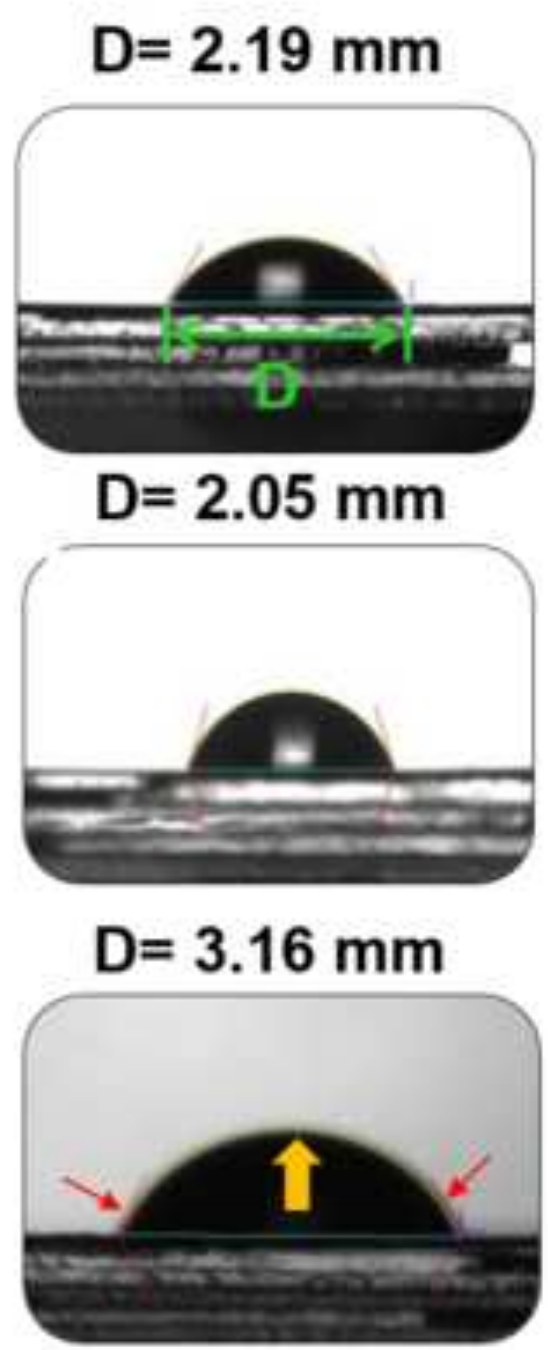

$\mathrm{t}=15 \mathrm{~min}$
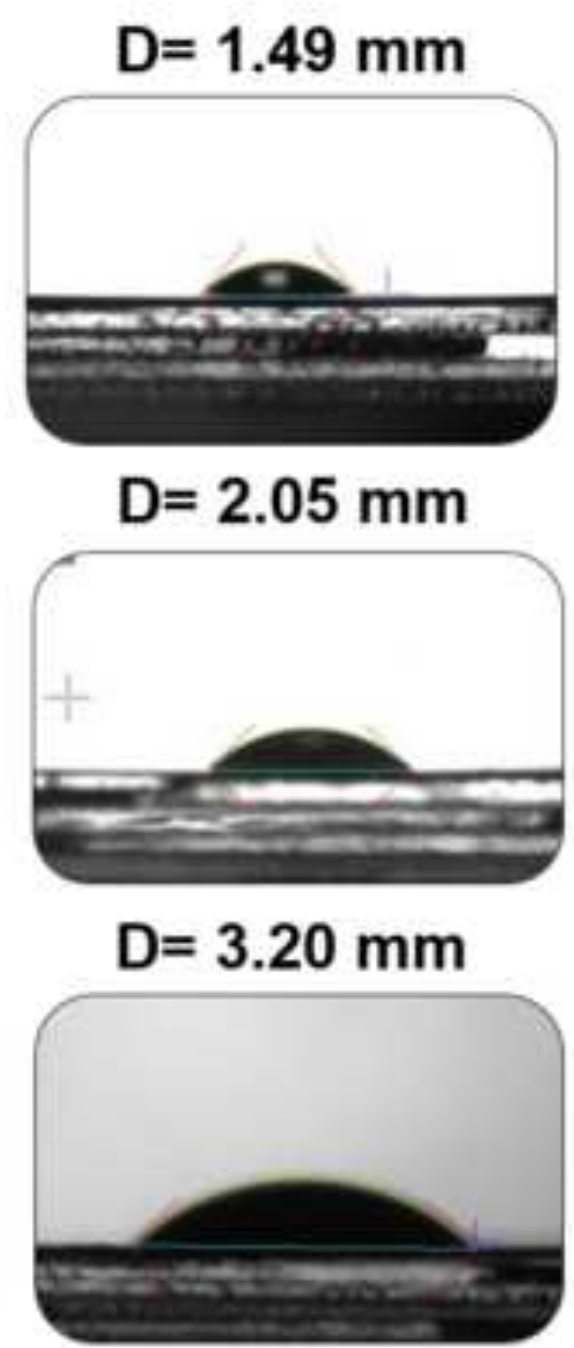

$\mathrm{t}=\mathbf{2 5} \mathrm{min}$
Drop evaporation
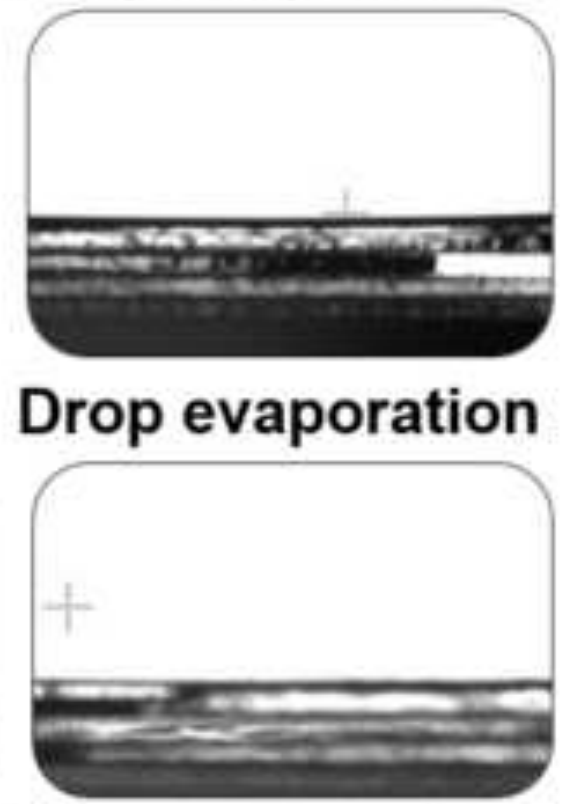

Drop evaporation

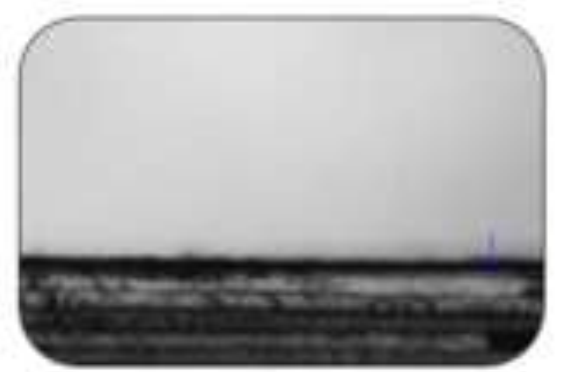

$$
\mathbf{t}=\mathbf{3 0} \mathrm{min}
$$

Time 


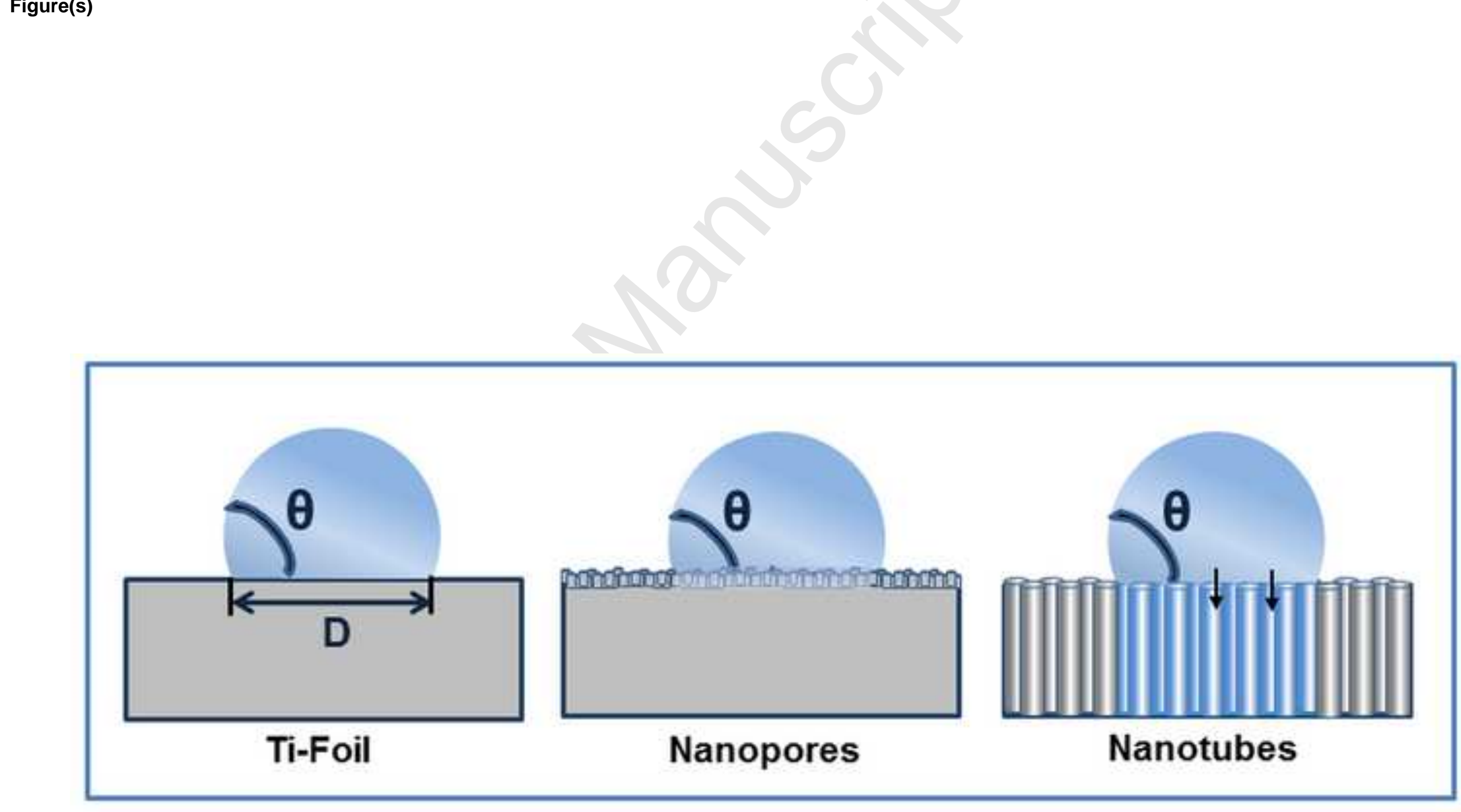

.

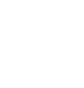

$\sqrt{2}$

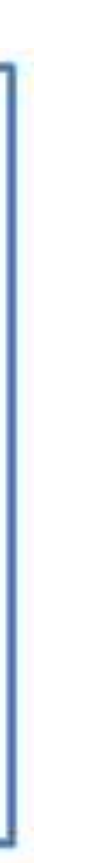

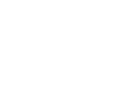

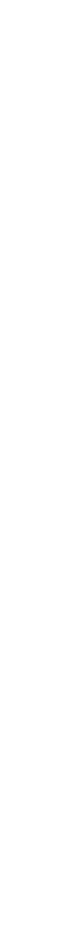

(1)

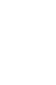

.

.

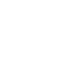




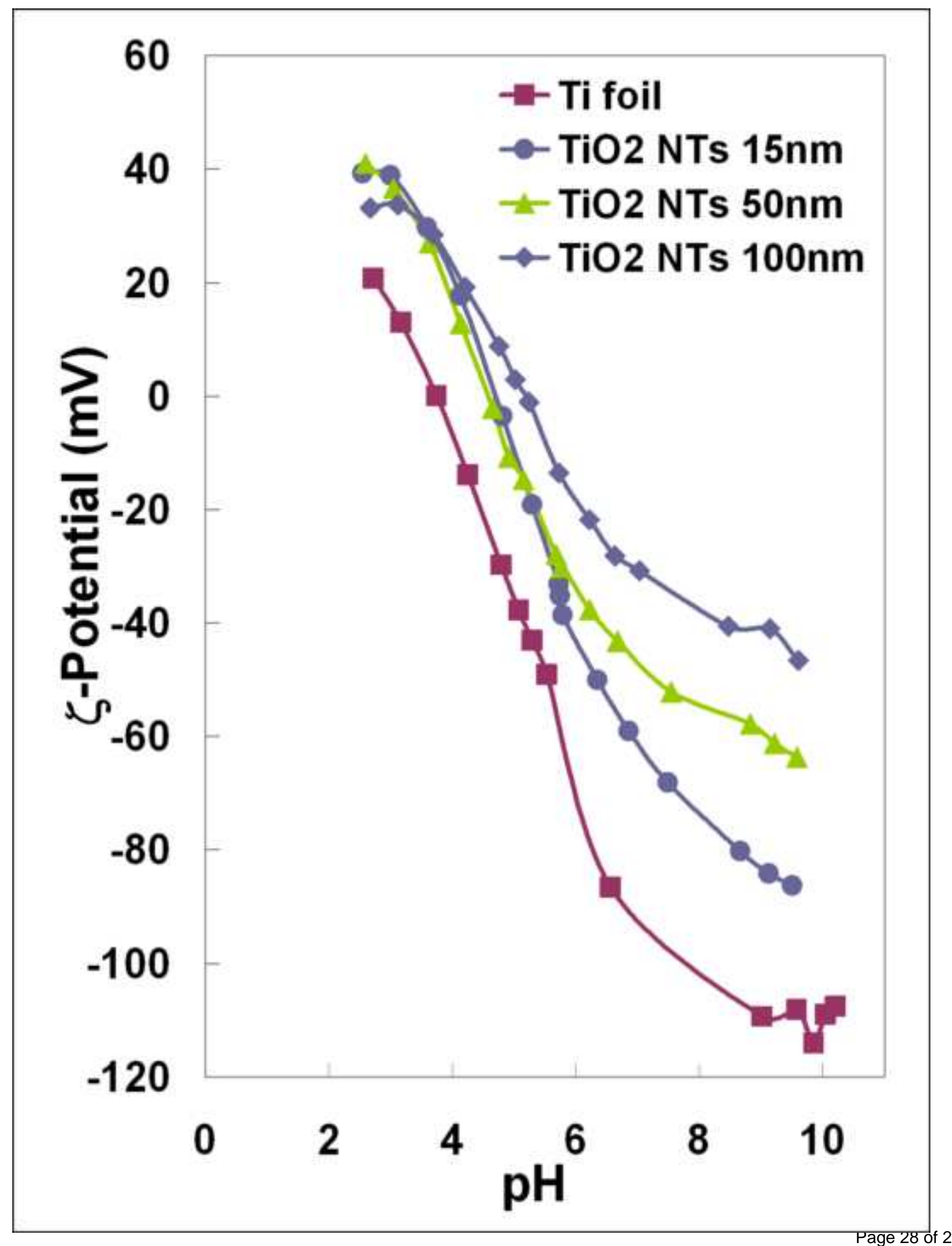

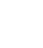



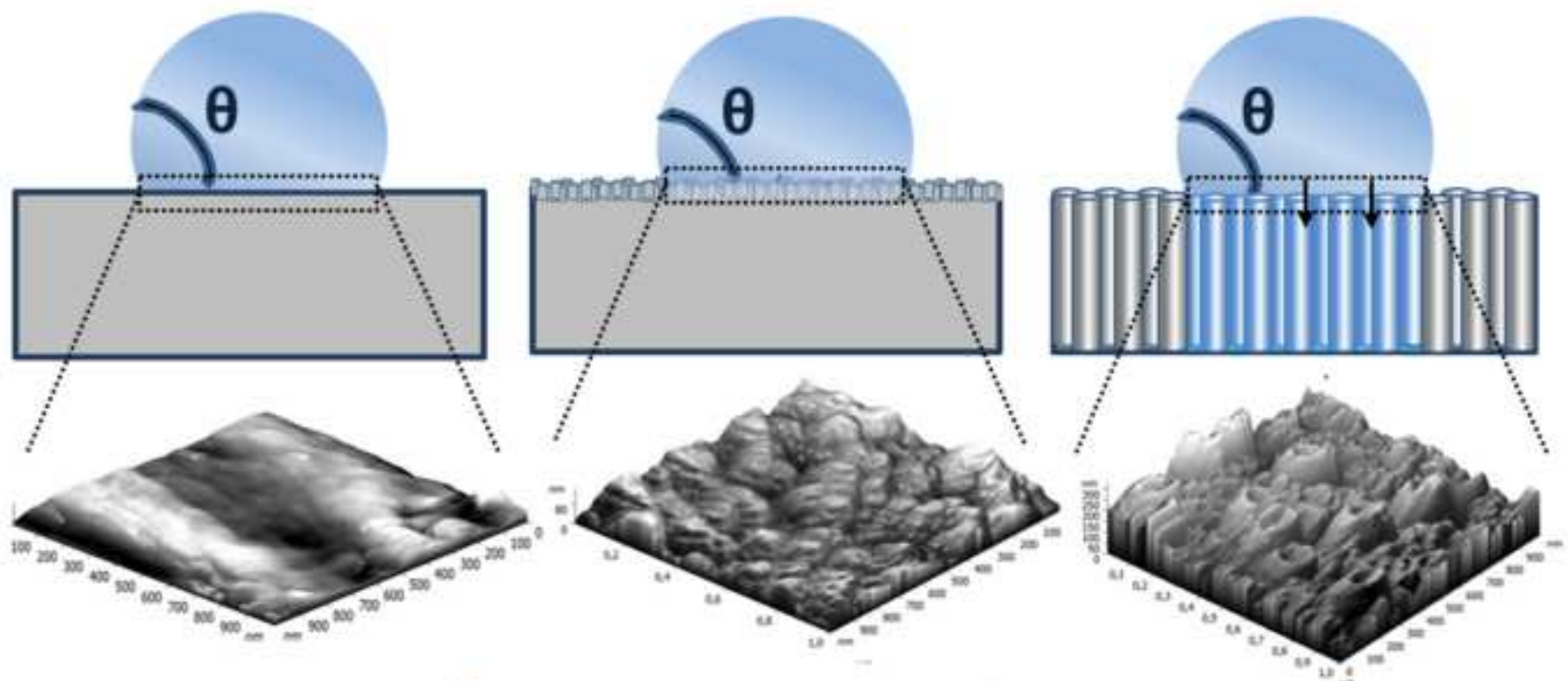

Wetting of Nano-rough Ti-Surfaces 